delivered in the historic lecture theatre of the Royal Institution. The first of the lectures, at which the Prime Minister will preside, is to be delivered as we go to press, on Wednesday, May 2, by Sir William Bragg on "The Development of the Principles of Refrigeration"; and the second, on Wednesday, May 30, by Lord Rutherford on "Helium and other Rare Gases". It is hoped to arrange for two further lectures of the same type to be delivered in the autumn.

The particular aim of these Research and Development Lectures is to enable legislators, administrators and other responsible leaders to make contact with outstanding achievements of practical science. There is no lack of interest in scientific work and thought among most of these representatives of progressive national life, but few lectures have been specially designed to appeal to them. Lord Melchett's action in providing for such lectures has, however, been warmly supported by men of science and laymen alike, and we congratulate him and the British Science Guild upon the success of a notable national endeavour.

\section{Progress of Automobile Engineering}

Fon the James Forrest Lecture which he delivered at the Institution of Civil Engineers on May 1, Sir Henry Fowler took as his subject "The Progress of Automobile Engineering'. After a tribute to Forrest, whom he had known when a student, Sir Henry said that to-day the automobile industry is the fifth in point of size in Great Britain, while in the United States in 1928 the industry used no less than $6,000,000$ tons of steel. The industry is also one of the greatest consumers of rubber, cotton and light alloys. The first self-propelled vehicle was that built in 1769 by Cugnot, and this was followed by those of Murdoch and Trevithick. Between 1823 and 1840, many patents were taken out for steam carriages, and the same period saw the experiments of Hancock, Gurney, Dance and others. Of the details then invented, the chain drive and differential gear of Hills and the steering gear of Gibbs has survived. Prohibitive tolls, vested interests and the railways, however, led to the abandonment of these early experiments and then came the "Red Flag" Act of 1865 , with restrictions which were not removed until 1896. But the matter was taken further by the work of Otto in 1876 and Daimler in 1883, the latter giving us a power unit which has changed our lives, much as the railway did a century ago. The outstanding personality of the early period of automobile development was Levassor, whose arrangement of the various parts of a motor-car has been followed generally. Progress from about 1895 until 1901 can be traced from the records of trials, one of the most important of these being that held by the Royal Automobile Club in 1900, when eighty-three cars, most of foreign origin, started on a 1,000 miles run.

A GREat part of the lecture was devoted to the details of the subject-materials, tyres, engines, gears, clutches, springs, brakes, etc. Improvements in materials have been continuous and have led to the introduction of various alloy steels and alloys of aluminium such as duralumin, "Y" alloy and that known as "R.R.". The investigation of these light alloys has led to an almost new technique. Recently, success has been achieved with a lead-bronze alloy for bearings. As for the tyres, pneumatic tyres were first conceived by Thomson in 1846, and developed by Dunlop in 1888 and first made for motors by Michelin and Co. In 1906 it was said that tyres cost "perhaps five or six times what the fuel cost per mile run", but the cost to-day is probably less than one quarter of the cost of fuel. In engine design the greatest advance of recent times has been the development of engines for using heavy oil. Compared with the petrol engine, the compression-ignition oil engine is slightly heavier, but has a higher efficiency and greater turning moment at low speeds. The problem of transmission, perhaps, is given more consideration to-day than any other. Many alternatives to the 'crash' gear have been tried, and not only in automobile but also in other classes of engineering, the matter has proved one of the most difficult problems in mechanics to be solved at a low cost and with high efficiency. In connexion with this part of his subject, Sir Henry described the Wilson gear, the Austin-Hayes gear, the Leyland hydraulic converter, the so-called fluid fly-wheel and the automatic clutch manufactured under the Newton patents. He also touched upon types of brakes, and methods of suspension, and in his conclusion recalled the remark of a friend that in early days cars were extremely simple and extremely unreliable, whereas at the present time they are extremely complicated, but leave nothing to be desired so far as reliability is concerned.

\section{Spicer-Dufay Colour Film}

Since 1926 the Spicer-Dufay process of colour photography has been the object of very intensive research and a demonstration of colour films made by this process was given at a Royal Society soiree in 1931 (see Nature, May 30, 1931, p. 821). It is stated that the new product will shortly be marketed for $16 \mathrm{~mm}$. cinematography, and later it is intended to supply also roll films for ordinary cameras and standard $35 \mathrm{~mm}$. cinematograph film. The new film consists of a transparent base on which is first coated a three-colour mosaic of regular pattern; in intimate contact with the colour mosaic screen is a very thin waterproof layer and above this is a highly sensitive panchromatic photographic emulsion. Exposure is made through the film base and colour mosaic. A positive image is formed by reversal. In principle, the process is thus similar to many which have long been operated with great success for still photography in colour.

ThE application of this general principle to cinematography has necessitated a very thprough study of every detail of the process. For example, in still photography it has been found quite satis. factory to use an irregular colour mosaic, the primary coloured elements being distributed in an entirely 